\title{
Beta-adrenergic stimulation of energy expenditure and forearm skeletal muscle metabolism in lean and obese men
}

Citation for published version (APA):

Blaak, E. E., van Baak, M. A., Kemerink, G. J., Pakbiers, M. T., Heidendal, G. A. K., \& Saris, W. H. M. (1994). Beta-adrenergic stimulation of energy expenditure and forearm skeletal muscle metabolism in lean and obese men. American Journal of Physiology (Consolidated), 267(2), E306-E315.

https://doi.org/10.1152/ajpendo.1994.267.2.E306

Document status and date:

Published: 01/01/1994

DOI:

10.1152/ajpendo.1994.267.2.E306

Document Version:

Publisher's PDF, also known as Version of record

Please check the document version of this publication:

- A submitted manuscript is the version of the article upon submission and before peer-review. There can be important differences between the submitted version and the official published version of record.

People interested in the research are advised to contact the author for the final version of the publication, or visit the DOI to the publisher's website.

- The final author version and the galley proof are versions of the publication after peer review.

- The final published version features the final layout of the paper including the volume, issue and page numbers.

Link to publication

\footnotetext{
General rights rights.

- You may freely distribute the URL identifying the publication in the public portal. please follow below link for the End User Agreement:

www.umlib.nl/taverne-license

Take down policy

If you believe that this document breaches copyright please contact us at:

repository@maastrichtuniversity.nl

providing details and we will investigate your claim.
}

Copyright and moral rights for the publications made accessible in the public portal are retained by the authors and/or other copyright owners and it is a condition of accessing publications that users recognise and abide by the legal requirements associated with these

- Users may download and print one copy of any publication from the public portal for the purpose of private study or research.

- You may not further distribute the material or use it for any profit-making activity or commercial gain

If the publication is distributed under the terms of Article $25 \mathrm{fa}$ of the Dutch Copyright Act, indicated by the "Taverne" license above, 


\title{
$\beta$-Adrenergic stimulation of energy expenditure and forearm skeletal muscle metabolism in lean and obese men
}

\author{
E. E. BLAAK, M. A. VAN BAAK, G. J. KEMERINK, \\ M. T. W. PAKBIERS, G. A. K. HEIDENDAL, AND W. H. M. SARIS \\ Department of Human Biology, University of Limburg and Department of Nuclear Medicine, \\ University Hospital Maastricht, 6200 MD Maastricht, The Netherlands
}

Blaak, E. E., M. A. van Baak, G. J. Kemerink, M. T. W. Pakbiers, G. A. K. Heidendal, and W. H. M. Saris. $\beta$-Adrenergic stimulation of energy expenditure and forearm skeletal muscle metabolism in lean and obese men. Am. $J$. Physiol. 267 (Endocrinol. Metab. 30): E306-E315, 1994.The effect of $\beta$-adrenergic stimulation on whole body energy expenditure and forearm skeletal muscle metabolism was investigated in lean and obese men. Whole body energy expenditure was determined during rest and during intravenous infusion of increasing doses of the nonselective $\beta$-agonist isoprenaline (Iso). Forearm skeletal muscle metabolism was investigated with Iso infusion with and without simultaneous infusion of the $\beta_{1}$-blocker atenolol $\left(A^{\prime} \mathbf{T}\right)$ by measuring skeletal muscle blood flow (SMBF) and arteriovenous concentration differences of various metabolites. 'The changes in SMBF were estimated from forearm total (venous occlusion plethysmography), skin (laser doppler), and fat tissue blood flow (133Xe washout). The increase in whole body energy expenditure with Iso was similar in lean and obese subjects. With Iso, the rise in arterial or arterialized glycerol and nonesterified fatty acids (NEFA) was lower in obese than lean subjects, which may reflect a lower $\beta$-adrenergically mediated lipolysis in obesity. During infusion of increasing doses of Iso, the respiratory exchange ratio decreased significently in lean subjects but not in the obese subjects, which indicates a more pronounced increase in fat oxidation in lean subjects. This is confirmed by the clata on skeletal muscle metabolism, where NLFA uptake was increased in lean subjects, whereas the obese subjects showed a tendency toward an increased glucose uptake and a significantly increased lactate release. With Iso plus AT (mainly (32-adrenergic stimulation), both groups showed an increased skeletal muscle lactate release. In conclusion, although the thermogenic response to Iso was similar in lean and obese subjects, the utilization of fat seems to be impaired in obesity.

thermogenesis; obesity, symputhetic nervous aystem; fat utilization

THE ISSUE OF WHE'IHER OBESI'Y develops as a result of a metabolic efficiency is still a matter of dispute. Although it has been reported that a predisposition to obesity may lie in a lowered resting energy expenditure (25), once the obese state has developed an elevated energy expenditure proportional to the increased lean body mass equals energy intake (34). Obesity has also been associated with a diminished thermogenic response to catecholamines (21) or to ingestion of nutrients (2), but these findings are not colzsistent $(10,31)$. Recent lines of evidence suggest that one of the factors contributing to the obese state may be an impaired utilization of fat as a fuel, which will result in the development and maintenance of large fat stores. A low ratio of fat to carbohydrate oxidation has been reported to be associated with subsequent weight gain in Pima Indians (36). Additionally, in Pima Indian women, free fatty acid turnover and lipid oxidation rates (expressed per $\mathrm{kg}$ body fat) decreased with increasing degree of obesity (23). Further, a recent study indicated that fatter men combusted less fat than lean men during an exercise load, which may be related to muscle fiber type (32).

The sympathetic nervous system plays an important role in the regulation of energy expenditure and fuel metabolism. Catecholamines can influence hepatic and skeletal muscle glucose turnover (26). Also, lipolysis in adipose tissue increases as a result of catecholamine infusion (20), and this may be indirectly related to the increased whole body energy expenditure (19). With regard to protein metabolism, a diminished or unchanged protein turnover has been reported as a result of $\beta$-adrenergic stimulation $(14,24)$. The close association between the sympathetic nervous system, energy expenditure, and fuel metabolism, especially the crucial role of the sympathetic nervous system in the mobilization of fat stores, indicates that any alteration in the activity of the sympathetic nervous system may lead to a metabolic abnormality in obesity.

In a previous study, we showed that the thermogenic response to sympathomimetics is mainly mediated via $\beta_{1}$-and $\beta_{2}$-adrenoceptors (7). Furthermore, Astrup et al, (3) found as result of ephedrine stimulation an increased whole body oxygen consumption and suggested that at least $50 \%$ of this increase may be located in skeletal muscle. These results combined with the abovementioned findings on a possibly impaired sympathetically mediated thermogenesis and fatty acid utilization in obese subjects have led to the present study. In this study, we investigated the effect of $\beta$-adrenergic stimulation on whole body energy expenditure and skeletal muscle substrate fluxes in lean and obese men. For stimulating metabolism the $\beta$-agonist isoprenaline (Iso) was used with and without simultaneous infusion of the $\beta_{1}$-blocker atenolol (AT).

\section{SUBJECTS AND METHODS}

In this study, nine lean and eight obese healthy male volunteers were selected on the basis of their percent body fat (lean $<20 \%$, obese $25-40 \%$ ) and age (between 20 and $40 \mathrm{yr}$ ). Physical characteristics of the subjects are indicated in Table 1. All subjects were normotensive and in good health, as assessed by a medical history and physical examination. Furthermore, both the lean and obese subjects spent no more than $3 \mathrm{~h}$ a week in organized sport activities. The study protocol was reviewed and approved by the Ethics Committeo of the University of Limburg, and all volunteers were asked for written consent. The experiments were performed after an overnight fast, and room temperature was kept between 21 and $23^{\circ} \mathrm{C}$. The study protocol consisted of two experiments 2 wk apart. In the first experiment the nonselective $\beta$-agonist 
Table 1. Physical characteristics of the subjects

\begin{tabular}{|c|c|c|}
\hline & Lean & Obese \\
\hline Age, yr & $25.2 \pm 1.7$ & $31.8 \pm 1.6^{\mathrm{b}}$ \\
\hline Weight, kg & $76.5 \pm 1.9$ & $108.4 \pm 8.1^{\mathrm{c}}$ \\
\hline $\mathrm{BMI}, \mathrm{kg} / \mathrm{m}^{2}$ & $23.0 \pm 1.5$ & $31.7 \pm 1.6^{\mathrm{c}}$ \\
\hline Body fat, $\%$ & $17.0 \pm 2.2$ & $31.3 \pm 1.8^{\mathrm{c}}$ \\
\hline
\end{tabular}

Values are means $\pm \mathrm{SE}$; obese: $n=8$ subjects, lean: $n=9 . \mathrm{BMI}$, body mass index. Unpaired $t$ test. ${ }^{b} P<0.01$, $P<0.001$

Iso was infused in increasing standardized doses, and during each infusion period whole body energy expenditure and plasma concentrations of Iso, norepinephrine (NE), and epinephrine (Epi) were determined (Iso infusion test). In the second experiment, forearm skeletal muscle metabolism was investigated during Iso infusion with and without simultaneous infusion of the $\beta_{1}$-blocker AT (forearm muscle experiment). To reduce the variability in the forearm muscle experiment, the dose of Iso infused in this experiment was individually determined in the Iso infusion test and was the dose that increased plasma Iso to a fixed concentration of $165 \mathrm{pg} / \mathrm{ml}$. In addition to this experiment the effect of a $60-\mathrm{min}$ infusion on several metabolic parameters was investigated in a small number of subjects (control study).

\section{Iso Infusion Test.}

In this experiment, Iso was infused in increasing doses of 6 , 12,23 , and $46 \mathrm{ng} \cdot \mathrm{kg}$ fat-free mass ${ }^{-1}(\mathrm{FFM}) \cdot \mathrm{min}^{-1}$, each dose for $30 \mathrm{~min}$. The dose is related to Iso sulfate, $69 \%$ of which corresponds to Iso free base. Body density was determined by hydrostatic weighing with simultaneous lung volume measurement (Volugraph 2000; Mijnhardt). Body composition was calculated according to the formula of Siri (29). Whole body energy expenditure was measured by an open-circuit ventilated hood system (Oxycon Beta; Mijnhardt). The abbreviated formula of Weir (33) was used for calculating energy expenditure. After $15 \mathrm{~min}$ in each infusion period, a venous blood sample was taken with a heparinized syringe and was put into a glutathione-containing tube in ice. The sample was immediately centrifuged at 3,000 revolutions $/ \mathrm{min}(\mathrm{rpm})$ at $4^{\circ} \mathrm{C}$, and the plasma was stored at $-50^{\circ} \mathrm{C}$. In the plasma samples, concentrations of Iso, Epi, and NE were determined by high-performance liquid chromatography (30). During the experiments, heart rate was recorded continuously. When the heart rate had risen 30 beats/min the infusion was stopped.

\section{Forearm Muscle Experiment}

Design. Forearm skeletal muscle metabolism was investigated during infusion of the nonselective $\beta$-agonist Iso with and without simultaneous infusion of the $\beta_{1}$-blocker A'T. After 30 min supine rest, skeletal muscle blood flow (SMBF) and arteriovenous concentration differences of various metabolites across muscle were determined (see Clinical methods and Biochemical methods). After the resting period the Iso infusion was started for $60 \mathrm{~min}$ with $\mathrm{AT}$ added the last $30 \mathrm{~min}$. The above-mentioned measurements were repeated after $30 \mathrm{~min}$ of Iso infusion and after $30 \mathrm{~min}$ of simultaneous Iso and AT infusion. For each subject, the dose of Iso (per kg FFM) leading to a plasma concentration of $165 \mathrm{pg} / \mathrm{ml}$ in the Iso infusion test was infused. The mean infusion rate of Iso was $18.8 \pm 1.5$ $\mathrm{ng} \cdot \mathrm{kg} \mathrm{FFM} \mathrm{F}^{-1} \cdot \mathrm{min}^{-1}$ (range $15.3-23.5 \mathrm{ng} \cdot \mathrm{kg} \mathrm{FFM}-1 \cdot \mathrm{min}^{-1}$ ) in lean subjects and $19.7 \pm 1.1 \mathrm{ng} \cdot \mathrm{kg} \mathrm{FFM}^{-1} \cdot \mathrm{min}^{-1}$ (range $15.7-26.1 \mathrm{ng} / \mathrm{kg} F F M$ ) in obese subjects. Before the simultaneous infusion of Iso and AT $\left(0.11 \mathrm{mg} \cdot \mathrm{kg} \mathrm{FFM}^{-1} \cdot \mathrm{h}^{-1}\right)$ started, a priming dose of AT $(0.08 \mathrm{mg} / \mathrm{kg} \mathrm{FFM})$ was administered within $5 \mathrm{~min}$. The changes in forearm SMBF were determined by measuring total forearm blood flow (TBF), skin and subcutaneous adipose tissue blood flow (ATBF), and forearm composition.

Clinical methods. Before the start of the experiment, three canulas were inserted. For the sampling of arterialized (lean subjects) or arterial (obese subjects) blood a canula was inserted in a superficial dorsal hand vein or under local anesthesia in the radial artery of the forearm, respectively. In the same arm, a second canula was inserted in a forearm antecubital vein for the infusion of Iso and AT. In the contralateral arm, a third catheter was inserted in retrograde direction in an antecubital vein of the forearm for sampling of deep venous blood. To obtain arterialized blood the hand was heated for $30 \mathrm{~min}$ before the first baseline sample was taken.

TBF was measured by venous occlusion plethysmography (35) with a mercury strain gauge (Periflow 0699; Janssen Scientific Instruments). The strain gauge was placed around the forearm, which contained the deep venous catheter. Because this method measures percent change in volume, the blood flow is related to $100 \mathrm{ml}$ forearm tissue. Before measuring TBF, the hand circulation was occluded by inflating a pediatric sphygmomanometer cuff, placed around the wrist, to a pressure of $200 \mathrm{mmHg}$. In this way, TBF could be assessed without interference from the hand circulation. The venous occlusion cuff, placed around the upper arm, was automatically inflated (and deflated) to a pressure of $40 \mathrm{mmHg}$. TBF was recorded approximately every $4 \mathrm{~s}$ (depending on heart rate) during $1.5 \mathrm{~min}$, and the consecutive (stable) values during the last minute were averaged.

Subcutaneous ATBF was measured on the dorsal side of the forearm $\sim 10 \mathrm{~cm}$ proximal to the wrist joint by the $1.3 \mathrm{Xe}$ washout method (22). A dose of $5.5 \mathrm{MBq}(150 \mu \mathrm{Ci})$ : $1: 3 \mathrm{Xe}$, dissolved in saline $(0.1-0.15 \mathrm{ml})$, was injected subcutaneously with a very fine needle. The arm was placed in a fixed position close to a large-field-of-view gamma camera (Technicare 438 HR; General Electric/CGR large field, Utrecht, 'The Netherlands). The registration of the $134 \mathrm{Xe}$ disappearance was started 45 min after injection to be sure that the washout was monoexponential. From the regression of count activity against time, the disappearance constant of ${ }^{13 i} \mathrm{Xe}$ over the last $20 \mathrm{~min}$ of each infusion period was determined to calculate fat tissue blood flow. It was assumed that the fat tissue-blood partition coefficient of Xe was $8 \mathrm{ml} / \mathrm{g}$ in both lean and obese subjects. For the conversion of the ATBF values from $100 \mathrm{~g}$ to $100 \mathrm{ml}$ tissue, the density of adipose tissue was assumed to be $0.9 \mathrm{~g} / \mathrm{ml}$ in both groups $(12,29)$.

Before the measurement of TBF, skin blood flow was determined by the laser. Doppler technique (Periflux PF3; Perimed) with an occluded hand circulation. The probe was placed on the ventral side of the forearm near the wrist joint. Resting skin blood flow was assumed to be $5 \mathrm{ml} \cdot 100$ $\mathrm{ml}^{-1} \cdot \min ^{-1}$, a value reported by Sejrsen (28) at an ambient temperature of $19-22^{\circ} \mathrm{C}$.

In obese subjects, the amount of subcutaneous fat, bone, and muscle of the forearm was determined by a cross-sectional analysis at the site of the greatest circumference with magnetic resonance imaging (Gyroscan T5, Philips Medical Sys. tems). In the lean subjects, the average forearm composition of another group of lean subjects $(n=10$, comparable age and body mass index), determined with the same magnetic resonance imaging (MRI) procedure as in the obese, was taken for calculating SMBF. With MRI, we could not determine the amount of forearm skin nor distinguish the amount of musde tissue from tendinous structures. 'Therefore, the relationship between the amount of forearm skin and the total amount of muscle and subcutaneous fat was assumed to be constant and was assumed to be as described by Cooper ot al. (12). The 
amount of tendon was calculated in a similar way by relating its amount to the amount of muscle. Under the heading of fat and muscle are also grouped nerves and blood vessels within these tissues. Taken together, SMBF was calculated by the following formula

$$
\begin{aligned}
\mathrm{TBF}= & \text { amount of muscle }(\% \text { total area } / 100) \times \mathrm{SMBF} \\
& + \text { amount of skin }(\% \text { total area } / 100) \times \mathrm{SBF} \\
& + \text { amount of fat }(\% \text { total area } / 100) \times \mathrm{A}^{\mathrm{l}} \mathrm{BBF}
\end{aligned}
$$

$$
\text { (units blood flow: } \mathrm{ml} \cdot 100 \mathrm{ml} \text { tissue } \mathrm{e}^{-1} \cdot \mathrm{min}^{-1} \text { ) }
$$

where SBF is skin blood flow.

In the lean subjects, energy expenditure was determined during the entire experiment with an open-circuit ventilated hood system. For practical reasons, we could not determine whole body energy expenditure during the forearm muscle experiment in obese subjects.

Control study. In three out of the nine subjects, the effect of a $60-\mathrm{min}$ period of Iso infusion on whole body energy expenditure, arterialized concentrations of nonesterified fatty acid (NEFA) and lactate, and IBB was investigated with the above-described methods. The infusion dose of Iso (per $\mathrm{kg}$ FFM) was the dose corresponding to a plasma concentration of $165 \mathrm{pg} / \mathrm{ml}$ (see Forearm Muscle Experiment).

Biochemical methods. Blood samples were taken simultaneously from the heated dorsal hand vein (lean), artery (obese), and the deep forearm vein after the blood flow measurement while the hand circulation was still occluded. Iriplicate samples of arterial and deep venous blood were immediately deproteinized with icencold sulfosalicylic acid $(3.5 \% \mathrm{wt} / \mathrm{vol})$ in a ratio of one to two, respectively. The samples were centrifuged at $3,000 \mathrm{rpm}$ at $44^{\circ} \mathrm{C}$. In the supernatant, concentrations of glucose, pyruvate, lactate, $\beta$-hydroxybutyrate, glutamate, alanine, and glutamine were determined with enzymatic assays automated on the Cobas Bio centrifugal analyzer at $355 \mathrm{~nm}$ (15). All assays were carried out using 0.2 $\mathrm{M}$ tris(hydroxymethyl)aminomethane-hydrazine buffer, $\mathrm{pH}$ 9.2, except for pyruvate, which was done with $1 \mathrm{M}$ phosphate buffer, pH 7.0. Plasma NEFA and glycerol were measured using standard enzymatic techniques automated on the Cobas Bio centrifugal analyzer.

The concentration of hemoglobin (Hb) in blood and the percentage saturation of $\mathrm{Hb}$ with $\mathrm{O}_{2}$ were measured with a hemoximeter (OSM2 hemoximeter; VA Howe Radiometer, Copenhagen, Denmark). The hematocrit was determined using a microcapillary system.

Calculations and statistics. The exchange of metabolites across muscle (nmol.100 $\mathrm{ml}$ muscle tissue-1. $\mathrm{min}^{-1}$ ) was calculated by multiplying the arteriovenous difference of metabolites ( $\mu \mathrm{mol} / \mathrm{l}$ ) by muscle blood flow ( $\mathrm{ml} \cdot 100 \mathrm{ml}$ muscle tissue $\left.{ }^{-1} \cdot \mathrm{min}^{-1}\right)$. The exchange of NEFA and glycerol was calculated by multiplying their plasma arteriovenous difference by plasma flow [muscle blood flow ( 1 - hematocrit/100)]. A positive flux indicates uptake.

Data are represented as means \pm SE. Both, in the lean and obese groups, the effects of Iso- and Iso plus $\mathrm{A}^{\prime} \mathrm{T}$ infusion on various parameters were analyzed with repeated-measurements analysis of variance (ANOVA). To analyze changes within groups, post hoc testing was done with a Student's paired $t$ test, and the $P$ values of the post hoc comparisons were corrected according to Bonferroni's inequalities. Differences between lean and obese subjects were tested with a one-way ANOVA. $P<0.05$ was regarded as statistically significant.

\section{RESULTS}

\section{Iso Infusion Test}

Both obese and lean subjects showed dose-related increases in plasma Iso (for lean and obese subjects: ANOVA: $P<0.001$ ), and the mean plasma concentrations with the increasing standardized doses (expressed per lkg FFM) were equal in the two groups (Fig. 1). Resting values of plasma NE or Epi were not signifi-
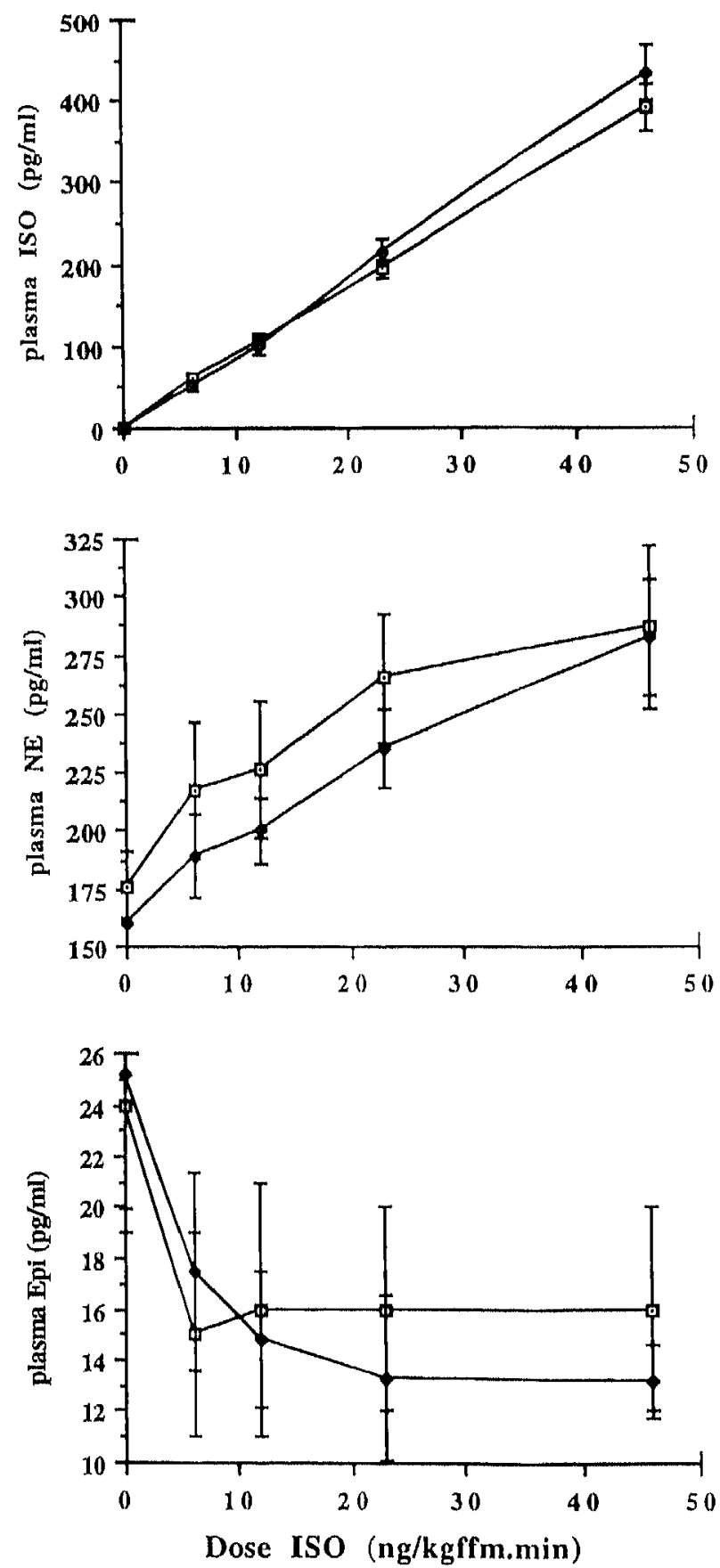

Fig. 1. Changes in plasma isoprenaline (Iso), norepinephrine (NE), and epinephrine (Epi) with infusion of increasing doses of $\beta$-agonist Iso in lean (CI) and obese $(\downarrow)$ subjects. Mean \pm SE; lean: $n=9$ subjects, obese: $n=8$. Repeated-measurements analysis of variance (ANOVA): lean and obese, plasma Iso: $P<0.001$; plasma NE: $P<0.001$; plasma Epi: $P<0.01$. FFM, fat-free mass. 
cantly different between lean and obese subjects (Epi: $24 \pm 5$ vs. $25 \pm 5 \mathrm{pg} / \mathrm{ml}, \mathrm{NE}: 176 \pm 16$ vs. $160 \pm 14$ $\mathrm{pg} / \mathrm{ml}$, respectively). Both groups showed similar plasma catecholamine responses during Iso infusion [an increase in plasma NE $(P<0.001)$ and a decrease plasma Epi $(P<0.01$, Fig. 1)].

Resting energy expenditure was significantly lower in the lean than the obese $(5.28 \pm 0.13$ vs. $6.29 \pm 0.34$ $\mathrm{kJ} / \mathrm{min}, P<0.05$ ), whereas energy expenditure expressed per unit FFM was not significantly different between lean and obese subjects (lean: $0.085 \pm 0.005$ vs. obese: $0.090 \pm 0.003 \mathrm{~kJ} \cdot \mathrm{kg} \mathrm{FFM}-1 \cdot \mathrm{min}^{-1}$ ). After 10 min of infusion of Iso, a steady state for whole body 'energy expenditure was reached; therefore, the mean of the last 20 min of each infusion period was taken as representative for the administered dose. There were no significant differences in the Iso-induced increases in energy expenditure between lean and obese subjects (for both groups: $P<0.001$ ), expressed either as absolute values ( $\Delta$ energy expenditure lean vs. obese: at $6 \mathrm{ng}$, $0.48 \pm 0.1$ vs. $0.57 \pm 0.12$; at $12 \mathrm{ng}, 0.71 \pm 0.1$ vs. $0.89 \pm 0.5$; at $23 \mathrm{ng}, 0.92 \pm 0.16$ vs. $1.35 \pm 0.15$; at 46 $\mathrm{ng}, 1.41 \pm 0.2$ vs. $1.72 \pm 0.2 \mathrm{~kJ} / \mathrm{min}$ ) or as percent increase (Fig. 2).

With Iso, there was a marked increase in the respiratory exchange ratio (RER) within the first $5 \mathrm{~min}$ of infusion most probably caused by a change in ventilation (7), which decreased again within the next $10 \mathrm{~min}$. The steady-state value for RER was therefore taken as the mean of the last 10 min of infusion. Resting values of the RER were similar in lean and obese subjects $(0.829 \pm 0.012$ vs. $0.825 \pm 0.013)$. During Iso infusion, this ratio decreased in the lean $(P<0.01)$, whereas there was no significant change in the obese subjects (Fig. 2)

Resting heart rate values were not significantly different in lean and obese subjects (58.8 \pm 2.4 vs. $65.2 \pm 3.1$ beats/min, respectively). Also, there were no significant differences in the Iso-induced increases in heart rate between lean and obese subjects (Fig. 2).

\section{Forearm Muscle Experiment}

Whole body thermogenesis and heart rate. During the forearm muscle experiment, we measured for practical reasons whole body energy expenditure only in lean subjects. There was a significant increase in whole body energy expenditure in lean subjects of $16 \%$ with Iso $(5.28 \pm 0.13$ vs. $6.14 \pm 0.17 \mathrm{~kJ} / \mathrm{min}, P<0.001)$ and of $8 \%$ with Iso plus AT $(5.28 \pm 0.13$ vs. $5.70 \pm 0.14 \mathrm{~kJ} /$ $\min , P<0.001$ ). The Iso-induced increase in energy expenditure during the forearm muscle experiment ( 30 min infusion, plasma Iso $165 \mathrm{pg} / \mathrm{ml}$ ) was comparable to the increase in energy expenditure at a plasma Iso concentration of $165 \mathrm{pg} / \mathrm{ml}$ during the stepwise infusion protocol (Iso infusion test). There was a slight decrease in steady-state values of RER with Iso infusion (from $0.83 \pm 0.01$ to $81 \pm 0.03, P<0.01$ ), whereas, with Iso plus $A T$, this value did not change significantly.

Resting heart rate values were not significantly different in lean and obese subjects (lean: $57.0 \pm 1.8$ and obese: $63.0 \pm 3.5$ beats $/ \mathrm{min}$ ). The increase in heart rate
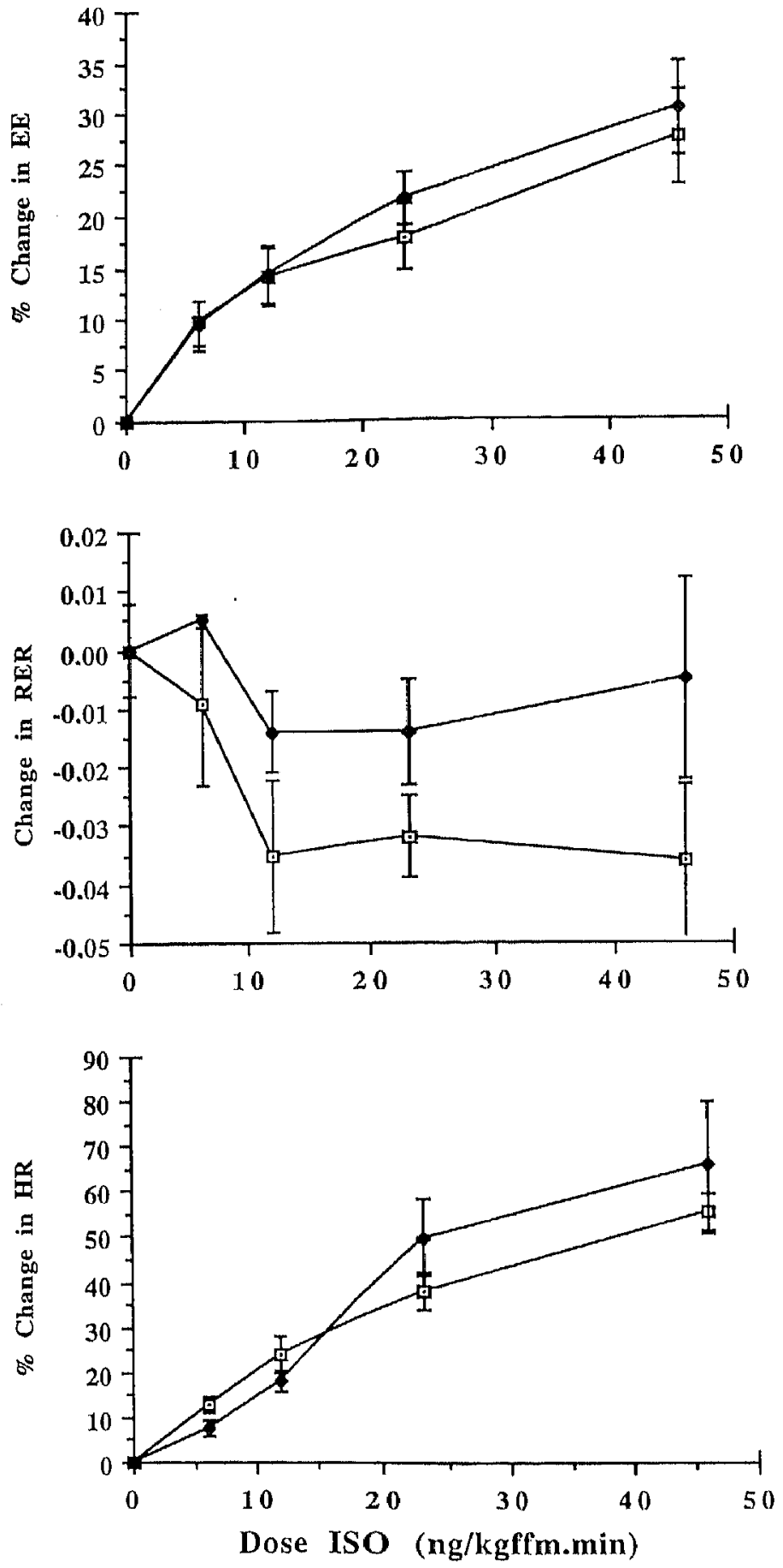

Fig. 2. Changes in energy expenditure (EB, as \%change), respiratory exchange ratio (RER), and heart rate (HR, as \%change) with infusion of increasing doses of $\beta$-agonist Iso in lean (1I) and obese $(\bullet)$ subjects. Mean $\pm \mathrm{SE}$; lean: $n=9$, obese; $n=8$. Repeated-measurements ANOVA: \%change EE and HR: $P<0.001$ for lean and obese; RER: $P<0.01$ for lean subjects.

at a plasma Iso concentration of $165 \mathrm{pg} / \mathrm{ml}$ did not differ significantly between lean and obese subjects, either expressed as absolute values (with Iso: $19.0 \pm 3.0 \mathrm{vs}$. $25.5 \pm 3.8$ and with ISO + AT: $11.4 \pm 2.3$ vs. $7.0 \pm 2.0$, respectively) or as percentage increase (Iso: $33.0 \pm 2.5$ vs. $36.9 \pm 5.0 \%$ and ISO + AT: $13.2 \pm 1.7$ vs. $11.7 \pm 3.0 \%$, respectively). 
Intermediary metabolites. Changes in arterial concentrations of metabolites within both groups are indicated in Table 2. In the resting state, glycerol concentration was significantly higher in obese than lean subjects, whereas lactate and NEFA concentration tended to be higher in obese subjects (not significant). In both groups, there were no changes in pyruvate, lactate, and glucose concentrations with Iso. With Iso plus AT, these concentrations were still unchanged in lean subjects, whereas in the obese subjects glucose concentrations decreased in comparison with control. With Iso, NEFA showed the most pronounced changes in both groups (a 3-fold increase in the lean and a 2 -fold increase in obese subjects), whereas glycerol increased almost twofold in the lean and did not significantly change in obese subjects. Both for NEFA and glycerol the changes with Iso are significantly higher in lean than obese subjects ( $\triangle \mathrm{NEFA}: 837 \pm 104$ vs. $529 \pm 45 \mu \mathrm{mol} / \mathrm{l}, P<0.01$, $\Delta$ glycerol: $55 \pm 6$ vs, $23 \pm 12 \mu \mathrm{mol} / \mathrm{l}, P<0.05$ ). Whole blood alanine decreased in both groups, whereas glutamate decreased only in the lean group. In both groups, there were no changes in glutamine concentration. Basal plasma insulin was significantly higher in the obese compared with lean subjects, so was the increase in insulin with Iso ( $\Delta$ plasma insulin: $21.1 \pm 7.0 \mathrm{vs}$. $6.8 \pm 0.9 \mathrm{mU} / \mathrm{l}, P<0.05)$ and ISO plus AT ( $\triangle$ plasma insulin: $6.8 \pm 2.4$ vs. $2.0 \pm 0.5 \mathrm{mU} / \mathrm{l}, P=0.05$ ).

Forearm composition. Total forearm area was 5,709 $\mathrm{mm}^{2}$ in lean subjects and $8,218 \mathrm{~mm}^{2}$ in obese subjects. Lean subjects had less subcutaneous fat than obese subjects when expressed as percentage of total forearm area $(14.4 \pm 0.9$ vs. $20.6 \pm 1.1 \%, P<0.01)$. The relative amount of muscle was comparable in lean and obese subjects (63.2 上 1.2 vs. $60.2 \pm 1.0 \%$, respectively). The relative amount of bone (expressed as a percentage of total forearm area) was lower in obese than lean subjects (lean: $7.1 \pm 0.6$ vs. obese: $4.5 \pm 0.3 \%, P<0.001$ ). The relative amounts of skin and tendon were, respectively, slightly higher and lower in the obese compared with lean subjects (skin: lean vs, obese, $8.8 \pm 0.1$ vs. $9.2 \pm 0.1$; $P<0.05$ and tendon: $6.5 \pm 0.1$ vs, $5.6 \pm 0.1, P<0.01$ ).

Blood flow. Table 3 shows the changes in blood flow through the different forearm tissues. Resting TBF and muscle blood flow were not different in lean and obese subjects, whereas the subcutaneous fat blood flow was significantly lower in the obese subjects. The relative units for skin blood flow were similar in lean and obese subjects ( $5.8 \pm 0.6$ vs. $5.2 \pm 0.6$, respectively), and there were no changes as a result of Iso or Iso plus AT infusion. TBF tended to increase more with Iso in lean than obese subjects ( $\triangle \mathrm{TBF}$ lean vs. obese: $2.87 \pm 0.87$ vs. $0.90 \pm 0.3 \mathrm{ml} \cdot 100 \mathrm{ml}^{-1} \cdot \mathrm{min}^{-1}, P=0.06$ ), and the increase in SMBF was significantly higher in lean subjects ( $\triangle \mathrm{SMBF}$ lean vs. obese: $4.12 \pm 1.25$ vs. $\left.1.26 \pm 0.48 \mathrm{ml} \cdot 100 \mathrm{ml}^{-1} \cdot \mathrm{min}^{-1}, P<0.05\right)$. With Iso plus $\mathrm{AT}$, fat blood flow returned to control values in obese subjects, whereas in the lean subjects there was a tendency toward an increase (between groups: $P<0.05$ ). In both lean and obese subjects the changes in TBF were mainly determined by SMBF.

Skeletal muscle substrate fluxes. Table 4 shows skeletal muscle substrate fluxes with Iso and Iso plus AT. There are no significant differences in resting skeletal muscle substrate fluxes between lean and obese subjects, although glucose flux tended to be lower in the lean subjects $(P=0.11$ ). Average values for deep venous oxygen saturation were $50.0 \pm 3.7 \%$ in lean subjects and $46.0 \pm 5.9 \%$ in obese subjects. With Iso, muscle oxygen uptake increased in the lean, whereas there was no significant change in the obese subjects. With Iso plus $\mathrm{AT}$, the oxygen flux in both groups was not significantly different from control. In lean subjects, the Iso-induced rise in oxygen consumption was accompanied by a significantly increased uptake of NEFA by muscle, whereas in the obese subjects glucose uptake and lactate release tended to increase. With Iso plus AT, lactate release was still increased in the obese and also showed a strong tendency to increase in the lean subjects (ANOVA: $P=0.07)$. Glycerol flux did not change in the lean subjects, whereas in obese subjects there was an increased release with Iso (paired $t$ test, Bonferroni: $P=0.06)$ and Iso plus AT $(P<0.05)$. The most pronounced differences in skeletal muscle metabolism between lean and obese subjects with Iso or Iso plus AT are summarized in Fig. 3.

Table 2. Arterialized (lean) or arterial (obese) concentrations of metabolites as result of infusion of the nonselective $\beta$-agonist $I_{\text {so }}$ with and without simultaneous infusion of the $\beta_{1}$-blocker AT in lean and obese subjects

\begin{tabular}{|c|c|c|c|c|c|c|c|c|}
\hline & \multicolumn{2}{|c|}{ Control } & \multicolumn{2}{|c|}{ Iso } & \multicolumn{2}{|c|}{$\mathrm{Iso}+\mathrm{AT}$} & \multicolumn{2}{|c|}{ ANOVA } \\
\hline & Lean & Obose & Lenn & Obese & Lean & Obose & Loan & Ohese \\
\hline Pysuvate & $80 \pm 6$ & $62 \pm 13$ & $86 \pm 6$ & $62 \pm 13$ & $88 \pm 5$ & $64: 10$ & & \\
\hline Lactate & $596=35$ & $785 \pm 83$ & $647 \pm 54$ & $775 \pm 61$ & $585 \pm 48$ & $687 \pm 56$ & & \\
\hline Glucose & $4,869 \pm 103$ & $4,948=136$ & $5,000 \pm 1.07$ & $5,055 \pm 130$ & $4,874 \pm 107$ & $4,720 \pm 83^{11, \mathrm{cl}}$ & & 0.04 \\
\hline Plasma NEFA & $412 \pm 45$ & $637 \pm 70$ & $1,249 \pm 118^{\circ}$ & $1,065 \pm 87^{\circ}$ & $471 \pm 42^{f}$ & $698 \pm 116^{d}$ & 0.001 & 0.001 \\
\hline Plasma glycerol & $70=4$ & $120+10 \mathrm{~K}$ & $124 \pm 70$ & $14.3 \pm 12$ & $70 \pm 3^{\Gamma}$ & $100 \pm 14^{d l}$ & 0.001 & 0.01 \\
\hline$\beta-\mathrm{OHB}$ & $110 \pm 40$ & $59 \pm 15$ & $217 \pm 71^{n}$ & $152 \pm 36^{b}$ & $164 \pm 67$ & $125 \pm 34^{\mathrm{a}}$ & 0.009 & 0.002 \\
\hline Glutamate & $140 \pm 8$ & $140 \pm 9$ & $114 \pm 71$ & $136 \pm 8$ & $119 \pm 8^{a}$ & $139 \pm 12$ & 0.001 & \\
\hline Alanine & $282 \pm 16$ & $323 \pm 22$ & $264 \pm 18^{n}$ & $290 \pm 15^{n}$ & $249 \pm 1.8^{b, d}$ & $269 \pm 18^{b}$ & 0.001 & 0.01 \\
\hline Glutamine & $551 \pm 17$ & 567 上21 & $557 \pm 22$ & $671 \pm 27$ & $553 \pm 27$ & $598 \pm 39$ & & \\
\hline Plasme insulin & $7.6 \pm 0.5$ & $15.7 \pm 3.6 \mathrm{~s}$ & $14,4 \pm 1.1 \mathrm{u}$ & 36.7 난 $10^{4}$ & $9.6 \pm 0.7^{b, 6}$ & $22.5 \pm 5.4^{a}$ & 0.001 & 0.001 \\
\hline
\end{tabular}

Values are means $\pm \mathrm{SE}$ in $\mu$ mol/l for all groups except; plasma insulin in which units are $\mathrm{mU} / \mathrm{l}$; lean: $n=9$, obese $n=11$. NEFA, nonesterified fatty acid; $\beta$-OHB, $\beta$-hydroxybutyrate. Paired $l$ test (Bonferroni's inequalities), Within groups, control vs, isoprenaline (Iso), Iso + atenolol (A'T): ${ } P<0.05, b P<0.01, \mathrm{~d} P<0.001$; Iso vs. Iso $+\mathrm{AT}$ : $\mathrm{d} P<0.05$, oP $<0.01, P P<0.001 ; P$ values $(<0.1)$ of analysis of variance (ANOVA) of repeated measurements within groups are indicated in right-hand columns. Between groups: control lean vs. obese: $t P<0.05$. 
Table 3. Forearm total, skin, skeletal muscle, and subcutaneous fat blood flow as a result of infusion of the nonselective $\beta$-agonist Iso with and without simultaneous infusion of the $\beta_{1}$-blocker $A T$ in lean and obese subjects

\begin{tabular}{|c|c|c|c|c|c|c|c|c|}
\hline \multirow{2}{*}{$\begin{array}{c}\text { Blood Flow, } \\
\mathrm{ml} \cdot 100 \mathrm{ml}^{-1} \cdot \mathrm{min}^{-1}\end{array}$} & \multicolumn{2}{|c|}{ Control } & \multicolumn{2}{|c|}{ Iso } & \multicolumn{2}{|c|}{$\mathrm{Iso}+\mathrm{AT}$} & \multicolumn{2}{|c|}{ ANOVA } \\
\hline & Lean & Obese & Lean & Obese & Lean & Obese & Lean & Obese \\
\hline $\begin{array}{l}\text { Total } \\
\text { Fat } \\
\text { Skin } \\
\text { Skeletal muscle }\end{array}$ & $\begin{array}{c}1.66 \pm 0.4 \\
2.29 \pm 0.4 \\
5.0 \\
1.26 \pm 0.56^{\mathrm{h}}\end{array}$ & $\begin{array}{c}1.54 \pm 0.83 \\
0.98 \pm 0.1^{g} \\
5.0 \\
1.46 \pm 0.50\end{array}$ & $\begin{array}{c}4.47 \pm 1.0^{\mathrm{a}} \\
3.79 \pm 0.96 \\
5.1 \pm 0.4 \\
5.46 \pm 1.57^{\mathrm{a}}\end{array}$ & $\begin{array}{c}2.44 \pm 0.3^{\mathrm{a}} \\
1.58 \pm 0.3 \\
4.9 \pm 0.1 \\
2.76 \pm 0.5\end{array}$ & $\begin{array}{c}2.97 \pm 0.8 \\
4.81 \pm 1.5 \\
4.9 \pm 0.5 \\
2.77 \pm 1.16\end{array}$ & $\begin{array}{c}1.89 \pm 0.2 \\
0.94 \pm 0.17^{\mathrm{d}} \\
5.0 \pm 0.2 \\
2.02 \pm 0.42\end{array}$ & $\begin{array}{l}0.005 \\
0.10 \\
0.004\end{array}$ & $\begin{array}{l}0.01 \\
0.05 \\
0.03\end{array}$ \\
\hline
\end{tabular}

Values are means $\pm \mathrm{SE}$; lean: $n=9$, obese $n=8$; Student's paired $t$ test (Bonferroni). Within groups, control vs. Iso, Iso $+\mathrm{AT}$ : a $P<0.05$; Iso vs. Iso + AT: d $P<0.05$; skeletal muscle blood flow vs, total blood flow: $\mathrm{h} P<0.05$. Between groups: control lean vs. obese: $\mathrm{g} P<0.01 . P$ values $(<0.1)$ of ANOVA of repeated measurements are indicated in right-hand columns.

Control study. Figure 4 shows the whole body thermogenesis and RER during a 60-min period of Iso infusion. The Iso-induced increase in energy expenditure remained constant during the infusion (mean increase: $19.0 \pm 1.3 \%$ ). The steady-state value of the RER decreased as a result of Iso infusion and remained constant throughout the infusion (rest: $0.79 \pm 0.01 ; 30 \mathrm{~min}$ Iso: $0.76 \pm 0.01 ; 60 \mathrm{~min}$ Iso: $0.75 \pm 0.02$ ). The arterialized concentration of NEFA increased about threefold and remained constant during the infusion, whereas there were no changes in the arterialized lactate concentration (Fig. 5). 'Tibi' ' restised as a result of Iso infusion and remained contivitit or slightly increased throughout the infusion.

\section{DISCUSSION}

\section{Iso-Induced Thermogenesis}

Obesity has been associated with a diminished thermogenic response during the infusion of sympathomimetics, but these findings are controversial $(10,21)$. In the present study the $\beta$-adrenergically mediated increase in energy expenditure (expressed as absolute or percentage increase) was similar in lean and obese men, so were the mean plasma Iso concentration and the Iso-induced nncrease in plasma NE and decrease in Epi. This indicates a normal thermogenic responsiveness to sympathomimetics in obese subjects, which is in line with findings of a recent study using Epi infusion (10). For practical reasons, we did not measure energy expenditure in the skeletal muscle experiment in obese subjects. In lean subjects the increases in energy expenditure with Iso and Iso plus AT (at a plasma Iso of $165 \mathrm{pg} / \mathrm{ml}$ ) were 16 and $8 \%$, respectively. Because the infused dose of the $\beta_{1}$-blocker Iso was sufficient for an effective $\beta_{1}$-blockade (11) and a high $\beta_{1}$-selectivity (7), the increase in energy expenditure with Iso plus AT can be mainly attributed to $\beta_{2}$-adrenergic stimulation. In addition, we showed in another study that both $\beta_{1^{-}}$and $\beta_{2}$-adrenoceptors are involved in human energy expenditure (7). It is known from literature that obesity does not exert any effect on the kinetics of the water-soluble $\beta_{1}$-blocker AT (16), which indicates that the achieved level of $\beta_{1}$-blockade must have been similar in lean and obese subjects. Under the assumption of a comparable level of $\beta_{1^{-}}$ blockade the similarity in the Iso-induced thermogenesis and heart rate responses (with Iso and Iso $+\mathrm{AT}$ ) suggests that the contribution of the $\beta_{1^{-}}$and $\beta_{2^{-}}$ adrenoceptors to whole body energy expenditure is comparable in both groups.

Although the whole body thermogenic response to Iso was similar in lean and obese subjects, there were pronounced differences in substrate metabolism with $\beta$-adrenergic stimulation. During infusion of increasing doses of Iso, there was a significant decrease in the RER in lean but not in obese subjects, which indicates a more pronounced increase in fat oxidation in lean subjects. This will be discussed more extensively under Forearm Muscle Metabolism.

Table 4. Skeletal muscle oxygen consumption and substrate fluxes as result of infusion of the nonselective $\beta$-agonist Iso with and without simultaneous infusion of the $\beta_{1}$-blocker AT in lean and obese subjects

\begin{tabular}{|c|c|c|c|c|c|c|c|c|}
\hline & \multicolumn{2}{|c|}{ Control } & \multicolumn{2}{|c|}{ Iso } & \multicolumn{2}{|c|}{ Iso + A' } & \multicolumn{2}{|c|}{ ANOVA } \\
\hline & Lean & Obese & Lean & Obese & Lean & Obese & Lean & Obose \\
\hline Oxygen & $3.8 \pm 1.0$ & $\begin{array}{c}5.5 \pm 0.9 \\
10+8\end{array}$ & $10.7 \pm 2.5^{\mathrm{a}}$ & $7.2 \pm 1.4$ & $6.8 \pm 2.4$ & $7.4 \pm 1.0$ & 0.003 & \\
\hline $\begin{array}{l}\text { Pyruvate } \\
\text { Lactate }\end{array}$ & $\begin{array}{c}14 \pm 6 \\
-11 \pm 14\end{array}$ & $\begin{array}{c}10 \pm 8 \\
-106 \pm 88\end{array}$ & $\begin{array}{l}56 \pm 26 \\
28 \pm 67\end{array}$ & $\begin{array}{c}27 \pm 11 \\
-395 \pm 162\end{array}$ & $\begin{array}{r}29 \pm 12 \\
-133 \pm 61\end{array}$ & $\begin{array}{c}36 \pm 8 \\
-383 \pm 63 n\end{array}$ & 007 & 005 \\
\hline Glucose & $191 \pm 60$ & $628 \pm 278$ & $431 \pm 188$ & $1,485 \pm 548$ & $361 \pm 131$ & $514 \pm 200$ & & $\begin{array}{l}0.00 \\
0.06\end{array}$ \\
\hline NEFA & $-2 \pm 18$ & $-2 \pm 70$ & $300 \pm 106^{n}$ & $-29 \pm 130$ & $-21 \pm 39^{d}$ & $89-193$ & 0.002 & \\
\hline Glycerol & $-12 \pm 6$ & $-3 \pm 12$ & $22 \pm 61$ & $-55 \pm 27$ & $-34 \pm 13$ & $-39 \pm 13^{n}$ & & 0.07 \\
\hline$\beta-\mathrm{OHB}$ & $9 \pm 9$ & $36 \pm 17$ & $119 \pm 57^{a}$ & $131 \pm 47^{a}$ & $-2 \pm 22$ & $63 \pm 23$ & 0.05 & 0.07 \\
\hline Glutamate & $31 \pm 6$ & $44 \pm 16$ & $34 \pm 12$ & $92 \pm 23$ & $37 \pm 14$ & $73 \pm 25$ & & \\
\hline Alanine & $-27 \pm 9$ & $-72 \pm 18$ & $-47 \pm 16$ & $-1.09 \pm 27$ & $-31 \pm 24$ & $-87 \pm 1.93$ & & \\
\hline Glutamine & $-42 \pm 17$ & $-68 \pm 28$ & $-46 \pm 24$ & $-76 \pm 14$ & $-53 \pm 49$ & $-31 \pm 44$ & & \\
\hline
\end{tabular}

Values are means $\pm \mathrm{SE}$ in $\mathrm{nmol} \cdot 100 \mathrm{ml}^{-1} \cdot \mathrm{min}^{-1}$ except for oxygen consumption in which units are $\mu \mathrm{mol} \cdot 100 \mathrm{ml}^{-1} \cdot \mathrm{min}^{-1} ;$ lean: $n=9$, obeso $n=8$; Student's paired $t$ test (Bonferroni). Within groups, control vs. Iso, Iso $+\mathrm{AT}$ : a $P<0.05$; Iso vs. Iso $+\mathrm{AT}$ : $\mathrm{d} P<0.05 ; P$ values $(<0.1)$ of ANOVA of repeated measurements are indicated in right-hand columns. 


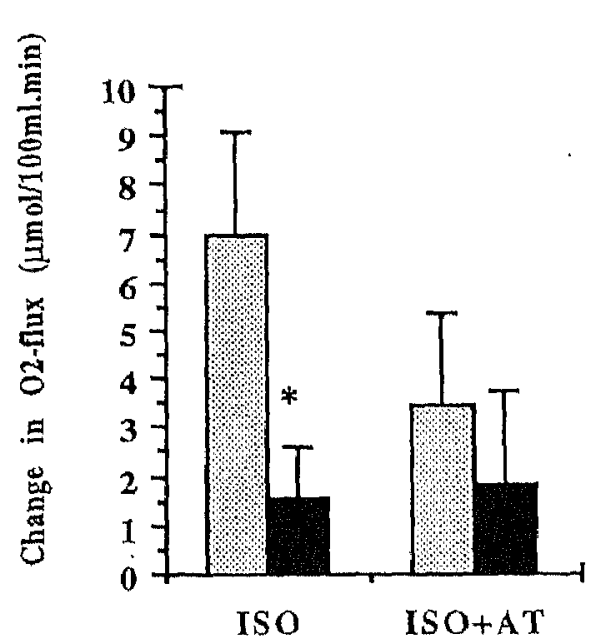

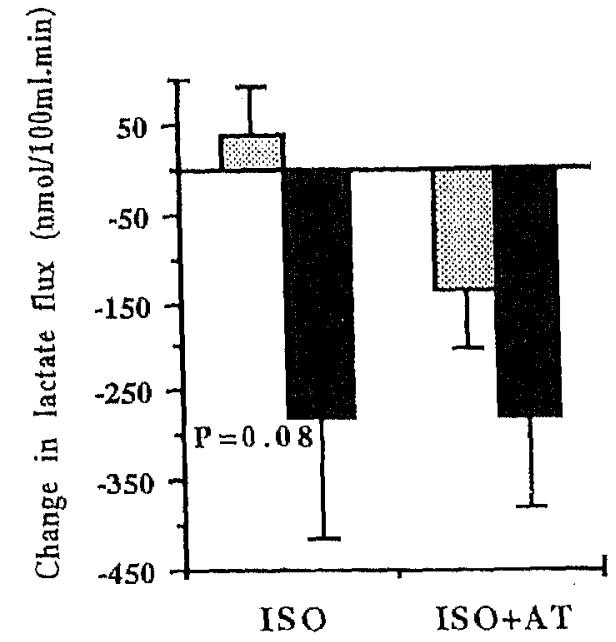

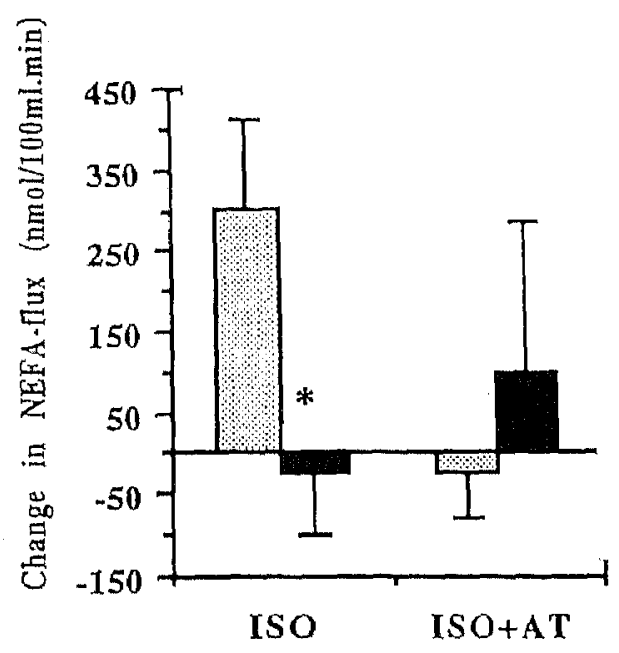

Fig. 3. Changes in skeletal muscle oxygen, lacate, glucose, and nonesterified fatty acid (NEFA) flux as result of infusion of $\beta$-agonist Iso with and without

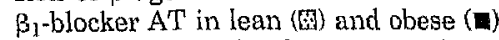
subjects. Mean $\pm \mathrm{SE}$; lean: $n=9$, obese: $n=8$. One-way ANOVA: $* P<0.05$.

\section{Iso-Induced Lipolysis}

The rise in arterial glycerol and NEFA during Iso infusion is lower in obese than lean subjects, which may indicate an impaired adipose tissue lipolytic response to $\beta$-adrenergic stimulation in obese subjects. Second, since insulin is an important inhibitor of lipolysis, the higher insulin concentrations during Iso infusion in obese subjects may also be an explanation for the lower lipolysis. Important in this respect is that we cannot exclude a difference in insulin resistance of adipose tissue between lean and obese subjects (13). In addition to this, in lean volunteers, it has recently been shown that the effects of insulin on lipolysis in vivo may be strongly counteracted by $\beta$-adrenergic stimulation (19). Thus whether the different degrees of hyperinsulinemia during Iso infusion in lean and obese subjects could have been implicated in the differences in plasma NEFA and glycerol remains questionable. A third factor that may contribute to differences in the Iso-induced release of glycerol and NEFA is the magnitude of the $\beta$-adrenergically mediated blood flow response. Recent experiments in our laboratory have shown that the ability to increase abdominal ATBF as a result of $\beta$-adrenergic stimulation is less in obese than in lean subjects (unpublished observations), which may suggest an association be- tween the impaired mobilization of fat stores and the lowered blood flow response in obese subjects. Further research is, however, required to elucidate the mechanisms behind the impaired lipolytic response in obese subjects.

In contrast to the lower circulating NEFA and glycerol concentrations with sympathetic stimulation in obese than lean subjects, basal glycerol levels were higher in the obese, which may indicate an increased basal lipolysis in obese subjects. However, basal glycerol, expressed per kilogram fat mass, decreased with increasing degree of obesity $(r=0.7, P<0.001)$, which indicates an impaired lipolysis in the obese subjects. The abovementioned findings suggest that both in the resting state and after thermogenic stimulation the obese subjects cannot make use of their (increased) fat stores as efficiently as lean subjects.

\section{Forearm Muscle Metabolism}

Methodological considerations. A factor that might disturb the results when comparing forearm skeletal muscle metabolism in lean and obese subjects is that the contribution of the different forearm tissues to TBF may be different. Therefore, SMBF was estimated by determining total subcutaneous fat and skin blood flow 

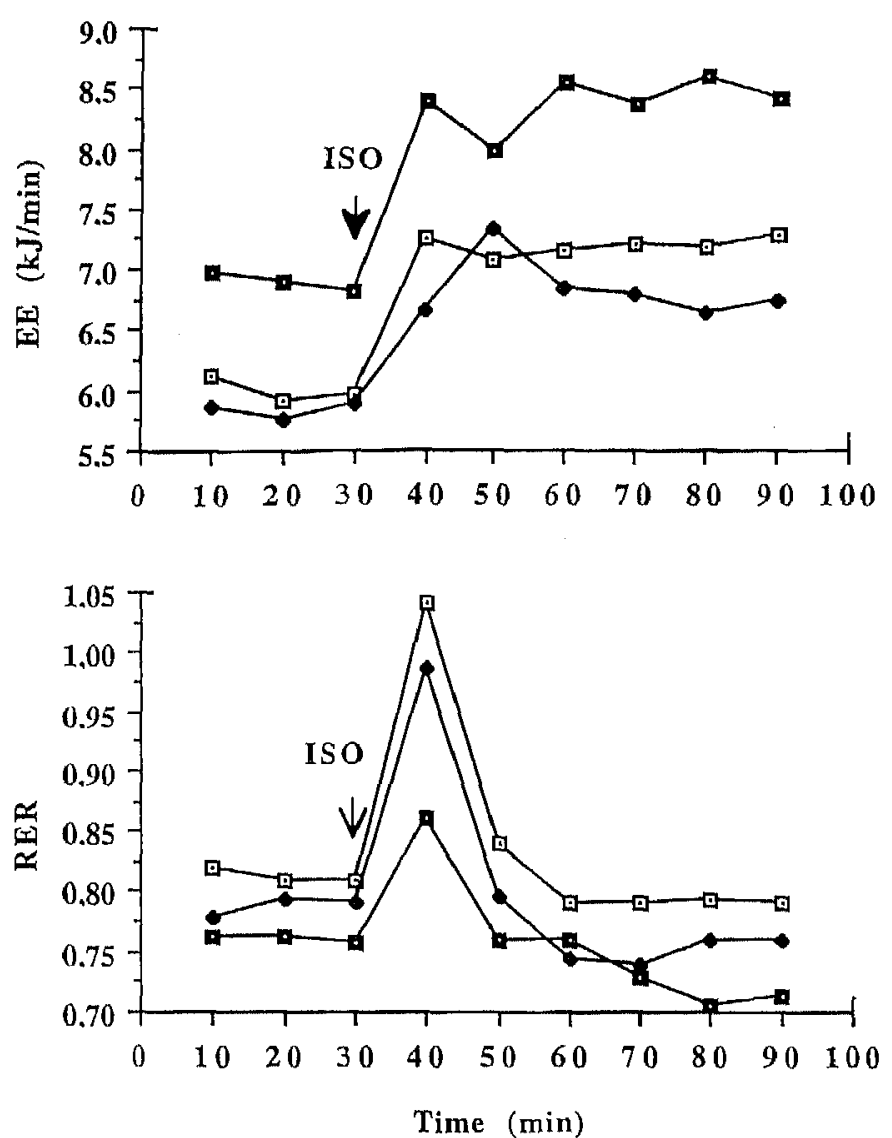

Fig. 4. Whole body EE and RER during 60 min-period of Iso infusion in 3 subjects.

and by measuring forearm composition. Skin blood flow was measured by the laser doppler method. Relative blood flow values were similar during rest, Iso, and Iso plus AT infusion, which indicates that, in both groups, there were no large changes in skin blood flow throughout the experiment. In both groups, resting skin blood flow was assumed to be $5 \mathrm{ml} \cdot 100 \mathrm{ml}^{-1} \cdot \mathrm{min}^{-1}$, as reported by Sejrsen (28) at a comparable ambient temperature. Because the relative units for skin blood flow were similar in lean and obese subjects, it seems reasonable to assume that there were no large differences in absolute resting skin blood flow between both groups. Moreover, even if there was a slight difference in resting blood flow between lean and obese subjects that was not detected by the laser doppler method (i.e., $2 \mathrm{ml} \cdot 100$ $\mathrm{ml}^{-1} \cdot \mathrm{min}^{-1}$ ), this would not affect the conclusions of this study. In addition, for calculating forearm fat blood flow from the washout of ${ }^{133 \mathrm{Xe}}$, the tissue-blood partition coefficient must be known. The tissue-blood partition coefficient was assumed to be $8 \mathrm{ml} / \mathrm{g}$ in both lean and obese subjects. However, when comparing lean and obese subjects, differences in this partition coefficient have to be taken into account since this coefficient may vary with the degree of body fatness. Variations in the lipid fraction of subcutaneous adipose tissue within the range reported by Bülow and co-workers (40-90\%; Ref. 8) would result in a variation in the partition coefficient from 4.6 to $9.6 \mathrm{ml} / \mathrm{g}$, as can be calculated on the basis of data of Chen et al. (9). The assumption of an average partition coefficient of 4.6 in lean subjects and 9.6 in obese subjects would yield slightly higher values for $\mathrm{SMBF}$ in the lean subjects (control vs. Iso vs. Iso + AT: $1.67 \pm 1.00$ vs. $5.86 \pm 1.27$ vs. $3.11 \pm 0.83 \mathrm{ml} \cdot 100 \mathrm{ml}$ muscle tissue ${ }^{-1} \cdot \mathrm{min}^{-1}$ ) and slightly lower values in the obese subjects (control vs. Iso vs. Iso + AT: $1.40 \pm 0.41$ vs. $2.60 \pm 0.52$ vs. $1.98 \pm 0.83 \mathrm{ml} \cdot 100 \mathrm{ml}$ muscle tissue $\mathrm{e}^{-1} \cdot \mathrm{min}^{-1}$ ). Correcting the partition coefficient for the lipid content of adipose tissue would therefore make the observed differences in muscle NEFA and oxygen flux between lean and obese subjects (slightly) more pronounced. The results of the present study show that the changes in TBF are mainly determined by changes in SMBF in both lean and obese subjects (Table 3). The
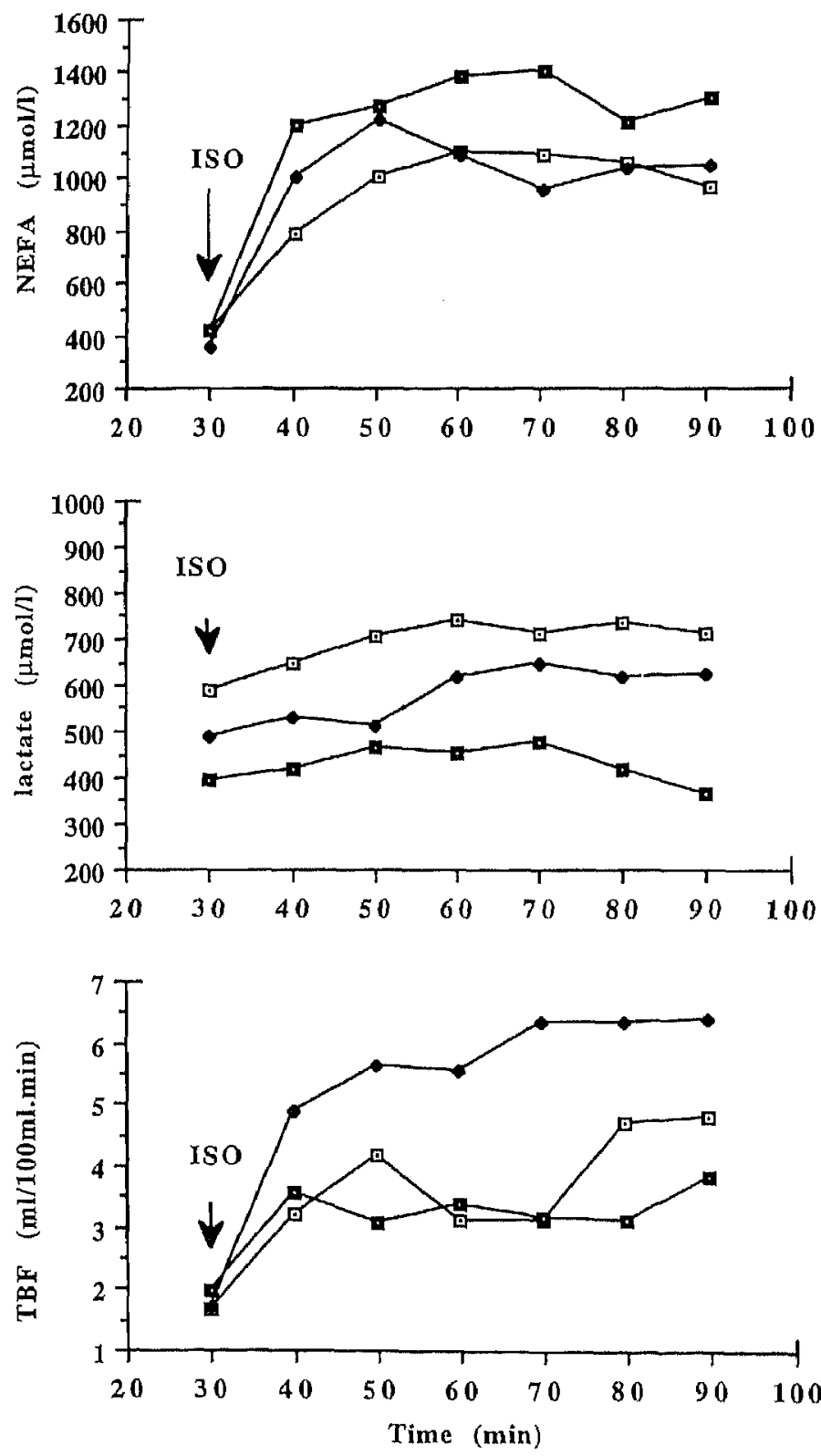

Fig. 5. Arterialized concentrations of NEFA and lactate and total forearm blood flow (TBF) during 60 min-period of Iso infusion in 3 subjects. 
use of TBF instead of muscle blood flow for the calculations of muscle substrate metabolism would therefore only slightly affect the results and would not alter the conclusions of this study.

Furthermore, the lean subjects were studied by using arterialized blood (warm air box; Ref. 6), whereas in the obese subjects direct arterial sampling took place. The warm air box method has been adequately validated for the determination of most metabolites (15). The method of hand heating has been criticized when applied by means of warming blankets since it may affect the distribution of blood flow to the contralateral arm (4). However, in a previous study, we showed that hand heating by a warm air box (4-h period) had no or a very slight effect on body and skin temperature, deep venous oxygen saturation, TBF, and glucose-induced oxygen consumption of the contralateral forearm (6). On the basis of these findings, we can exclude that the use of the warm air box method in lean subjects has interfered with the pronounced differences in intermediary metabolism in lean and obese subjects.

Iso infusion. As a result of Iso infusion the TBF response tended to be higher in lean than obese subjects $(P=0.06)$, whereas the Iso-induced SMBF response was significantly higher in lean subjects $(P<0.05)$. A lowered TBF response in obesity has been reported previously after oral glucose loading (5).

The lowered increase in fat oxidation and the impaired adipose tissue lipolytic response as a result of $\beta$-adrenergic stimulation in obese subjects compared with lean subjects is confirmed in our data on muscle metabolism in which we found a significantly increased muscle NEFA uptake in lean subjects but not in the obese subjects. The increased NEFA uptake in the lean subjects was accompanied by an increased muscle oxygen consumption, which suggests an increased NEFA oxidation. In contrast, in obese subjects, glucose seems to be the preferred substrate above fat, which is reflected in an increased muscle glucose uptake and lactate release. The latter findings suggest an increased glycolysis that may be accompanied by an increased glycogenolysis and glucose oxidation, as reported with epinephrine infusion (26). In both groups, there were no significant changes in skeletal muscle glutamate, glutamine, and alanine fluxes, indicating that there were no major changes in amino acid oxidation as a result of Iso infusion. Furthermore, the slight increase in skeletal muscle oxygen consumption during Iso in obese subjects did not reach statistical significance, which indicates that skeletal muscle is less important in the Iso-induced thermogenesis in obese compared with lean subjects. Taken together, in obese subjects, skeletal muscle fatty acid uptake and/or oxidation with $\beta$-adrenergic stimulation seems to be impaired, which is compatible with a recent study reporting a lower fractional fatty acid oxidation (\% total plasma flux) with Epi infusion in obese than lean subjects (10). A factor contributing to the diminished Iso-induced muscle fatty acid uptake in the obese subjects may simply be the lower increase in arterial fatty acid concentrations in obese than lean subjects (17). Second, it may be that, due to a lower proportion of slow-twitch type 1 oxidative muscle fibers, the obese are not able to oxidize fatty acids as efficiently as lean subjects, as recently suggested (32). Third, it has been shown that the membrane transport of long-chain fatty acids may be under $\beta$-adrenergic control (1), which implicates that differences in the activation of this transport between lean and obese subjects may contribute to the observed differences in muscle fatty acid uptake. However, at present, evidence is lacking to support this speculation.

Iso and AT infusion. With the continued infusion of Iso (2nd $30 \mathrm{~min}+\mathrm{AT}$ ) without a baseline period in between, there is a risk of tachyphylaxis of adrenoceptors. For this reason, we performed a control study in a small number of subjects in which the effect of prolonged Iso infusion (60 min) on several metabolic parameters was investigated. The finding that tachyphylaxis did not occur for the thermogenic response, RER, arterialized lactate concentration, and TBF makes it very unlikely that the continued infusion of Iso has interfered with the Iso plus AT results.

With Iso plus AT, both groups showed an increased muscle lactate release, which may indicate, as mentioned above, an increased glycolysis and glycogenolysis, which may be accompanied by an increased glucose oxidation (26). The changes in whole body thermogenesis with Iso in the obese and with Iso plus AT in both groups were not reflected in changes in skeletal muscle oxygen consumption, whereas the changes in skeletal muscle substrate fluxes suggest that skeletal muscle is of importance in the $\beta_{2}$-mediated component of thermogenesis. This apparent discrepancy may be due to the relatively large standard error in the measurement of skeletal muscle oxygen flux, which makes it unlikely to detect a small increase in whole body energy expenditure at the skeletal muscle level.

In conclusion, although the thermogenic response to Iso is similar in lean and obese subjects, there are pronounced differences in substrate metabolism. In obese subjects, the Iso-induced increase in the mobilization of fat stores is impaired compared with lean subjects. In addition, despite a twofold elevation in arterial NEFA concentrations, there is no change in uptake by muscle in obese subjects, which suggests an impaired ability of muscle to take up or oxidize fat. This lowered utilization of fat may favor the storage of triglycerides and the maintenance of large fat stores.

We thank the Department of Radiology of the University Hospital Maastricht, The Netherlands, for making magnetic resonance imaging equipment available for the determination of forearm composition.

Address for reprint requests: E. E. Blaak, Dept. of Human Biology, University of Limburg, PO Box 616, 6200 MD Maastricht, 'The Netherlands.

Received 2 November 1993; accepted in final form 13 April 1994.

\section{REFERENCES}

1. Abumrad, N. A., C. R. Park, and R. R. Whitesell. Catecholamine activation of the membrane transport of long chain fatty acids in adipocytes is mediated by cyclic AMP and protein kinase. J. Biol. Chem, 261: 13082-13086, 1986.

2. Astrup, A., T. Andersen, N. J. Christensen, J. Bülow, J. Madsen, L. Breum, and F. Quaade. Impaired glucose-induced 


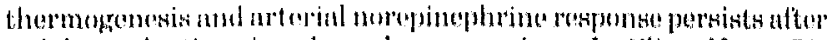

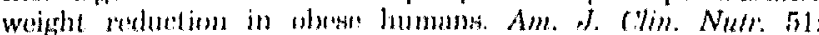
(3i) $-3337,1940$.

i. Astrup, A., J. Bülow, J, Madsen, and N. J. Christenson. Contribution of BAT" and akcletul musde to theomagenesis in

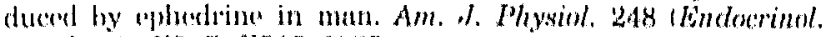

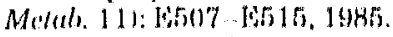

4. Astrup, A., L. Simonsen, J. Bülow, and N, J. Christengen. Metsumenent al' lonoum oxygen consumption: role of heating of

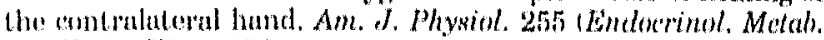

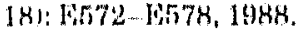

5. Buron, A. D., M. Iankwo, G. Brochtel, B. Hoit, C. Watt, and S. V. Rdelman. Retuced postprandial skeletal musele blond fow response contribules to glucose intolemanes in human obesity. $d$. (1in. Eindortinel. Molah. 70: 1525. 1533, 1990.

(i. Blauk, K, W. M. A. van Baak, K. P. G. Kermpen, and W, H, M. Saris. 'The allect of hand houting by a warm air box on oxygen consumption af the contraluteral arm. $/$. Appl. Physiol. 72 :

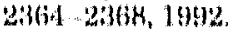

7. Blauk, H. B., M. A. van Bnak, K. P. G., Kempon, and W. H. M. Suris. Rolonfulpha and betu adrenoceptors in the sympatheticully-

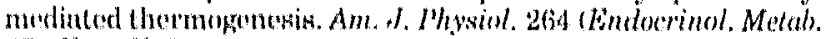
$271: 1411 \ldots 17,1998$.

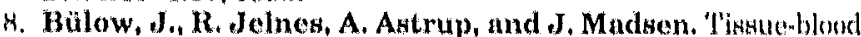

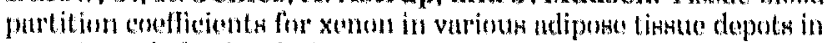

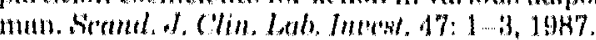

9. Chon, K. Y., F. Fun, S. Kim, K. Jan, S. Usami, and S. Chien.

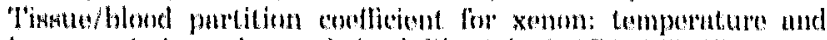

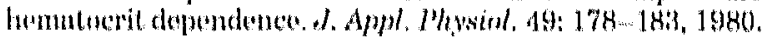

10. Connacher, A. A. W. M. Bennot, K. 'I', Jung, D. M. Btor, C. C.'T. Smilh, C.M. Soximpoour, and M. J. Ronnio. Gillect ol

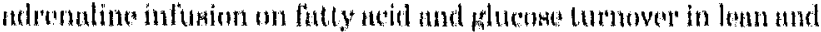

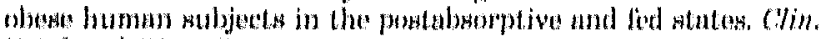

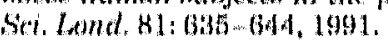

11. Conway, F. J. Ituman phomocokinotic aludies and pharmacoty.

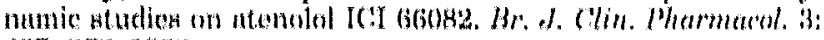
$267 \% 272,1992$

12. Cooper, K, R., O. G. Gdholm, and R. F. Mottram. 'The hlond

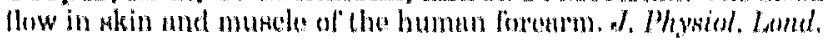
$124: 2542667,1955$.

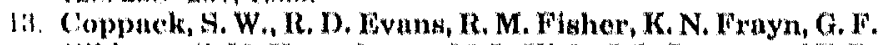
(ibbons, S. M. Mumphreys, M. C. Kirk, J. I. Potis, and 'T' D). R. Hocksduy. Arlipuso timstut molubolinm in obusity: lipuse action

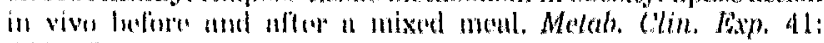
(i) $\left.2 i^{2}, 1+1,4\right)$

1. Dol Prato, S., R. A. Do Fronto, P', Gatellino, J. Wabren,

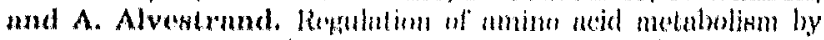

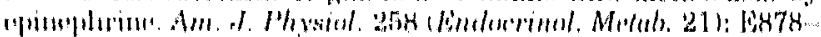
litiktr. I!!!11.

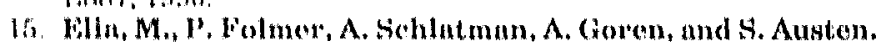

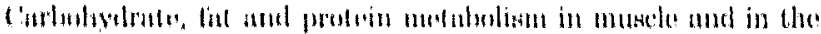

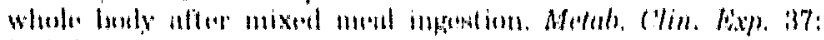

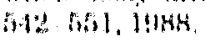

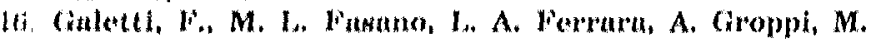

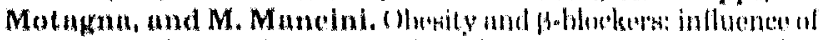

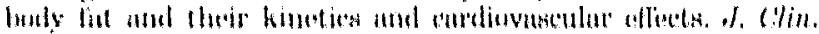

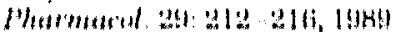

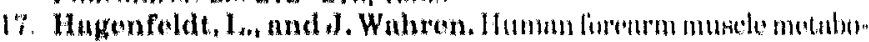

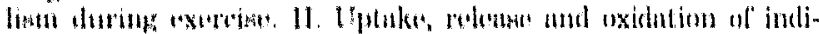

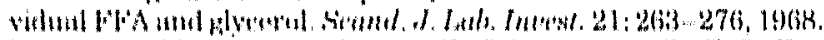

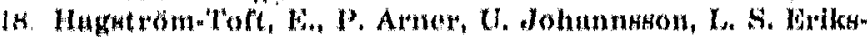

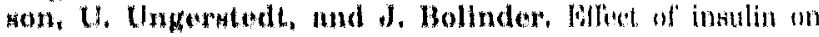

human adipose tissue metabolion in situ. Interactions with

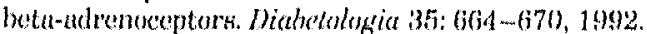

19. Havel, R. J., L. A. Carlsson, I. G. Ekolund, and A. Holmgren. Studies on the relation between mobilization of frece fatty acids and energy metabolikn in man: offects of norepinephrisc and nicotinic acid. Motab. Clin. Exp. 13: 1402-1411, 1964 .

20. Hehmdahl, $\mathrm{P}$, and B. Linde. Inlluence of cilculating N $\mathrm{N}$ and Epi on adipose tissue vasetulat resistance and lipolysis in humans. Am. d. Thysiol. 245 (Hean Circ. Physiol. 14): 14477-14452, 1983.

21. Jung, R. T., P. S. Shelty, W. P. T. James, M. Barrand, and M. Callingham. Reduced themogonesis in obesily. Nature? Lond. 279: $322,329,1979$.

22. Lamsen, O. A., N. A. Lassen, and F. Quande. Blood flow through human adipose tissue detormined with radionetive xo. non. Acta Physiol. Scand. 66: 337\% 345, 1966.

23. Lillioja, S., J. Foley, C. Bogardus, D. Mott, and I3. V. Howard. Pree facty acid metabolitim and obesily in man: in vivo and in vitro comparisons. Motal. Clin. Tixp. 35: $505 \% 514,1986$.

24. Matthews, D, E., G. Pesola, and R. G. Camploell. Eilied uf' epineplutine on amino acid and enerey metabolism in humans. Am. J. Physial. 258 (Endoctinol. Molab, 21): 18948-18956, 1990).

25. Ravussin, E., S. Lillioja, W. C. Knowler, L. Cristia, D. Freymond, W. G. H. Abbott, V. Boyce, B. V. Howard, and C. Bogardus, Reduced rute of energy expenditure as a risk fictor lor body woight ghin. N. Engt. J. Mod. 318: 467:472, 1988.

26. Raz, I, A. Katz, and M. K. Speneor. Hoingohrine inhibits

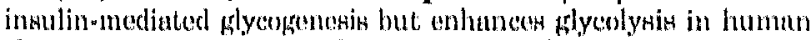

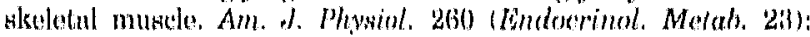

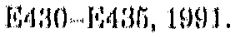

27. Segal, K. R., A. Gdano, und M. B. 'Tomas. 'llhertuic oflete al' a

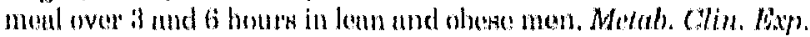
(3): $685,092,1990$.

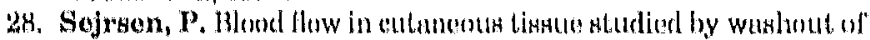

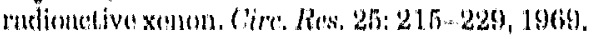

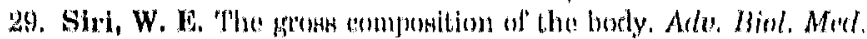

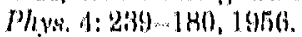

30. Smedes, F., J, C. Krank, and H. Poppe. Simplo und liant

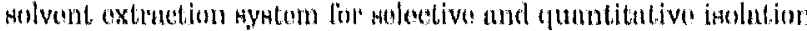
of" adromaline, noridenteline and dopamino from plasma and

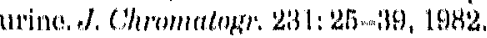

31. Vernot, O., C. A. Nught, L. Chubtin, Y. Sohutz, E. Dmuforih,

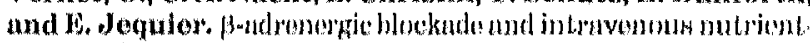

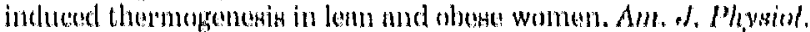

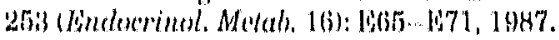

32. Wade, A. J., M. M. Murbut, and J. M. Round. Mumele fihn'

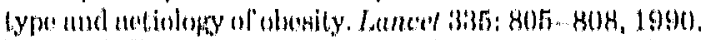

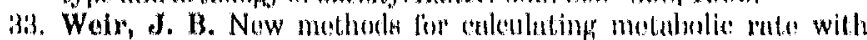

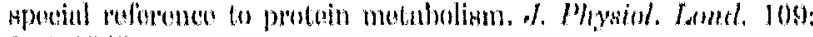
1. 0,1949

W. Wollo, S., G. B. Forbes, M. Statl, R, R. Barnard, and J. M.

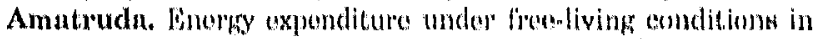
normal woight and ovorwelght women. Am, fl, Clin. Natr, b5: $14,21,1904$

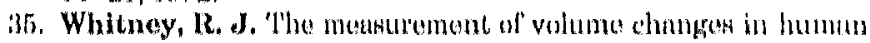

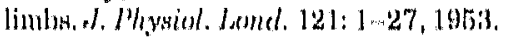

36. Zurlo, F., S. I Allioja, A. Esposito-Del Puonto, B. L. Nyomba, I. Rne, M. F. Snad, B, A. Swinburn, W. C. Knowler, C:

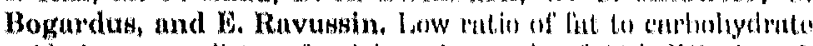

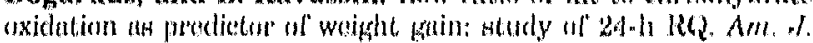

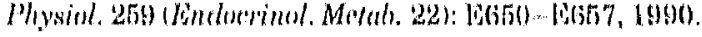

